\section{BMJ Open}

Ophthalmology

\title{
Factors influencing the episode duration and the anatomical and functional outcome in cases of acute central serous chorioretinopathy
}

\author{
Anil Parajuli (D) , ${ }^{1}$ Purushottam Joshi (D) ${ }^{2}$
}

To cite: Parajuli A, Joshi P. Factors influencing the episode duration and the anatomical and functional outcome in cases of acute central serous chorioretinopathy. BMJ Open Ophthalmology 2020;5:e000540. doi:10.1136/ bmjophth-2020-000540

Received 9 June 2020 Revised 21 0ctober 2020 Accepted 8 November 2020
(A) Check for updates

(C) Author(s) (or their employer(s)) 2020. Re-use permitted under CC BY-NC. No commercial re-use. See rights and permissions. Published by BMJ.

${ }^{1}$ Glaucoma, Mechi Eye Hospital, Birtamode, Nepal

${ }^{2}$ Retina, Pediatric Ophthalmolgy and Strabismus, Cataract, Mechi Eye Hospital, Birtamode, Nepal

Correspondence to Dr Anil Parajuli; anil. parajuli861@gmail.com

\section{ABSTRACT}

Objective To investigate the factors affecting the duration of subretinal fluid (SRF) resolution and their correlation with the final anatomical and functional outcome in cases of treatment naïve acute central serous chorioretinopathy (CSCR).

Methods and analysis We retrospectively studied 93 eyes of 93 patients diagnosed with treatment naive acute CSCR presenting within 30 days of onset of symptoms. The eyes were divided into two groups (1 and 2) based on the duration of SRF resolution; which was $\leq 3$ months in group 1 and $>3$ months in group 2. Demographic and medical history, and spectral domain optical coherence tomography features were noted and their association with duration for SRF resolution, final central macular thickness (CMT) and final best-corrected visual acuity (BCVA) were studied. All the patients were prescribed topical non-steroidal antiinflammatory drug for 1 month at the diagnosis of CSCR.

Results Longer duration of symptoms, female gender and baseline OCT factors like hyper-reflective dots and retinal pigment epithelial bumps were associated with longer duration for SRF resolution $(p<0.001, p=0.04$, $p=0.001$ and $p=0.01$, respectively). The SRF resolution time had strong correlations with the final CMT $(r=-0.589$, $p<0.001$ ) and final BCVA in logarithm of minimum angle of resolution (LogMAR) $(r=+0.599, p<0.001)$. Group 2 eyes had worse final BCVA and thinner final CMT than Group 1 (both $p<0.001$ ). The final CMT of the patients of Group 1 was statistically thinner than the normal population $(p<0.001)$.

Conclusion Patient's baseline clinicodemographic and OCT features can be used to predict the course and visual outcome in cases of treatment naïve acute idiopathic CSCR.

\section{INTRODUCTION}

Central serous chorioretinopathy (CSCR) is one of the most common chorioretinal pathologies. It is classically characterised by one or multiple neurosensory retinal detachments with the occurrence of subretinal fluid (SRF), with or without presence of a clinically detectable pigment epithelial detachment (PED). ${ }^{1}$ CSCR usually affects middle-aged men, however, it can be seen in patients from 20 to 64 years of age. ${ }^{23}$ The mean age in

\section{Key Messages}

What is already known about this subject?

- Central serous chorioretinopathy (CSCR) is a selflimiting disease.

- Chronic CSCR is often associated with poor visual outcome.

\section{What are the new findings?}

Female gender and the presence of hyper-reflective dots (HRDs) and retinal pigment epithelial (RPE) bumps in the baseline 0CT are associated with longer duration for subretinal fluid resolution.

Patients with HRDs have poor final visual outcome.

\section{How might these results change the focus of} research or clinical practice?

In cases of CSCR, females and patients with HRDs and RPE bumps in baseline OCT might do better with interventions other than topical non-steroidal antiinflammatory drug.

various studies is noted to range from 39 to 51 years. ${ }^{34}$ There is male preponderance and the reported male to female ratio varies from $2.7: 1^{5}$ to $7: 1 .^{6}$

Various theories have been proposed regarding the possible cause of CSCR. However, recent investigations have suggested that choroidal vascular hyperpermeability may be the principal underlying pathology. ${ }^{7-10}$

Most cases of acute CSCR resolve spontaneously within 6 months and more than $80 \%$ of the patients regain a visual acuity of better than $20 / 30 .{ }^{11}$ However, $5 \%$ of patients may experience severe vision loss to $20 / 200$ or even worse because of chronicity and retinal pigment epithelial (RPE) atrophy. ${ }^{12}$

The chronicity of the SRF has been directly linked to the final anatomical and functional outcome of the CSCR patients. The presence of chronic SRF is believed to cause photoreceptor death resulting in permanent deterioration of vision. ${ }^{13}$ The mechanism is believed to be the hypoxic damage to the 
outer retina due to its prolonged separation from the RPE and choroid. ${ }^{14}$

Spectral domain optical coherence tomography (SD-OCT) has proven useful for the study of the cases of CSCR due to its non-invasive nature, excellent diagnostic value and its aid in treatment follow-up. Various features like PED, fibrin, RPE bumps, hyper-reflective dots (HRDs) in the intraretinal and/or subretinal layer, and disrupted ellipsoid zone are seen in the OCT in cases of CSCR, which help to predict the disease duration and the prognosis of the disease. ${ }^{15-17}$

A better understanding of these factors would help in early identification and treatment of the cases at higher risk of chronicity to prevent the damage of photoreceptor and RPE. The purpose of this study was to see the effects of the various baseline clinicodemographic and OCT features on the duration of the disease and the anatomical and functional outcome in cases presenting with treatment naïve acute idiopathic CSCR.

\section{MATERIALS AND METHODS}

This retrospective, descriptive study was conducted in accordance with the Declaration of Helsinki and good clinical practice guidelines. We obtained the consent for the use of data for research from all patients.

All enrolled patients were diagnosed as treatment naive acute idiopathic CSCR at Mechi Eye Hospital, Jhapa, Nepal, between January 2017 and November 2018. The diagnosis of acute CSCR required a visible or clinically suspected serous neuroretinal detachment of any part of the macula and its documentation by OCT. None of the patients enrolled in the study underwent fundus fluorescence angiography or OCT angiography. Only those cases with history of first episode, with symptoms occurring within the preceding 30 days were included in the study. In case of bilateral involvement, only the first eye to develop the condition was included. Cases needed to have a minimum follow-up of 6 months. The patients' final BCVA and final central macular thickness (CMT) were recorded at 6 months follow-up or after 1 month of resolution of SRF, whichever was longer. Exclusion criteria included: (1) neurosensory retinal detachment secondary to diseases other than CSCR; (2) severe media opacities; (3) advanced glaucoma; (4) trauma; (5) high myopia; (6) posterior uveitis; (7) age-related macular degeneration; (8) angoid streaks and (9) those associated with pregnancy and steroid intake. Patients who were given other forms of medication other than topical non-steroidal anti-inflammatory drug (NSAID) and those who developed recurrences within the study period were also excluded.

We recorded the patients' age, gender, history of smoking, hypertension, diabetes, previous history of CSCR and duration of symptoms. The patients underwent complete ophthalmic examination including: BCVA, slitlamp biomicroscopy (using a 90-diopter lens) on dilated pupil and OCT imaging. BCVA test was done using a trial frame and a projection-type Snellen chart by different

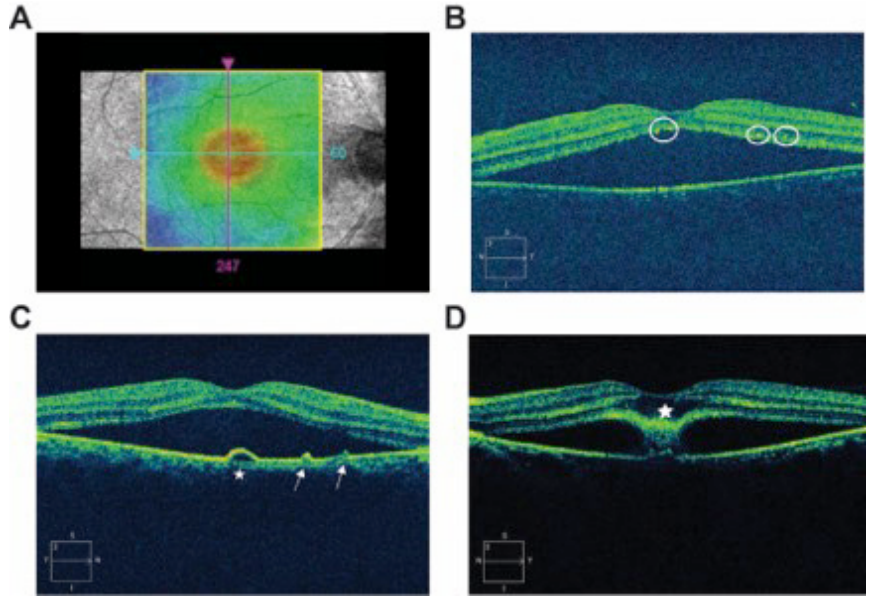

Figure 1 OCT image showing: Macular scan (A) hyperreflective dots (inside circle) (B); PED (star) and RPE bumps (arrow) $(C)$ and retinal 'dragging/dipping' with hyper-reflective flow in the subretinal spacesuggestive of fibrin (star) (D). PED, pigment epithelial detachment; RPE, retinal pigment epithelial.

optometrist but in the same room with standardised low light conditions. All OCT images were obtained through a dilated pupil using spectral domain OCT (Cirrus OCT, Carl Zeiss Meditec, Dublin, California, USA). The OCT scans were evaluated for: (1)CMT, (2) presence and number of HRDs, (3) presence of PEDs, (4) RPE bumps and (5) presence of fibrin in the SRF as shown in figure 1 by the $512 \times 128$ macular cube and Cirrus high definition (HD)-OCT enhanced HD 5 line Raster report. Both the scans were done in horizontal (temporal to nasal or vice versa) and vertical (superior to inferior) planes. RPE bump was defined as a slight elevation of the RPE layer without a hyporeflective area inside. ${ }^{17} \mathrm{We}$ (AP and PJ) counted the HRDs manually within an area of 1500 $\mu \mathrm{m}$ radius centred on the fovea using a horizontal raster scan. All the patients were treated with topical ketorolac $0.4 \%$ solution (Acular LS; Allergan, Irvine, California, USA) four times daily for 1 month on diagnosis of CSCR.

Patients were reviewed monthly for 6 months. On each visit, they underwent complete slitlamp biomicroscopy examination, BCVA evaluation and SD OCT. The patients were divided into two groups (1 and 2), based on the duration of SRF resolution from the first visit. Group 1 consisted of patients in whom the SRF resolution time was $\leq 3$ months and group 2 consisted of patients in whom the $\mathrm{SRF}$ resolution time was $>3$ months. We prospectively selected thirty eyes of 30 age-matched and sex-matched normal patients with no ocular and systemic comorbidity as control to calculate normal CMT for comparison. These individuals had come for regular eye evaluation.

The BCVA was converted to logarithm of the minimum angle of resolution (LogMAR) equivalent. We studied the various baseline clinicodemographic factors; the OCT parameters and their association with the SRF resolution time, the final CMT and the final visual outcome. 


\section{STATISTICAL ANALYSIS}

IBM SPSS Statistics for Macintosh, V.20.0., IBM was used for statistical analysis. We used the independent t-test to evaluate the difference between the groups in terms of age at presentation, duration of symptoms, baseline and final CMT, and baseline and final BCVA. We used the Pearson correlation coefficient ( $r$ ) to see the relationship between various factors. $\chi^{2}$ test and Fisher's exact test were used wherever applicable to assess the difference between the two groups by means of the various demographic features (gender, history of smoking, hypertension (HTN) and diabetes mellitus (DM) and the baseline OCT features (presence of HRDs, PED, RPE bumps and fibrin). We used the independent t-test to evaluate the effect of gender difference and the presence or absence of the various OCT features on the duration of SRF resolution, final CMT and final BCVA. The paired t-test was used to calculate the mean difference between the baseline and final BCVA and CMT of the study population. We performed the Mann-Whitney U test to see the difference between the two groups by the actual number of HRDs. Multivariate analysis of variance was done to determine if the duration of SRF resolution, final CMT and final BCVA were affected by the presence or absence of HRDs in the baseline OCT which was followed by a series of one-way ANOVA with a Bonferroni corrected alpha value for each AVOVA test as 0.01667. Multiple regression analysis was performed to predict final BCVA in LogMAR from both duration of SRF resolution and final CMT. Linear regression was performed to aid the visualisation of the relationship of different variables with each other and overlaid on the scatter plots.

\section{PATIENT AND PUBLIC INVOLVEMENT}

Patients were not directly involved in the planning of the study. The patients were part of a retrospective audit. Informed consent was obtained from patients whose data were used as control. They did not have to bear any extra financial burden due to their participation in the study.

\section{RESULTS}

There were 93 eyes of 93 patients diagnosed with treatment naïve acute idiopathic CSCR presenting within 30 days of onset of symptoms. Table 1 shows the comparison of the clinico-demographic features between the two groups. In group 1, there were 61 eyes of male and 6 eyes of female patients, and in group 2, 19 eyes of male and 7 eyes of female patients ( $p=0.03$, Fisher's exact test). The duration of symptoms in group 1 and 2 was $14.46 \pm 5.63$ days and $20.58 \pm 4.73$ days, respectively $(\mathrm{t}=-4.897, \mathrm{p}<0.001$, independent t-test). There was no significant difference between the two groups ( 1 and 2 ) by means of baseline BCVA in LogMAR $(0.47 \pm 0.37$ and $0.44 \pm 0.24$, respectively, $\mathrm{t}=0.355, \mathrm{p}=0.7$, independent $\mathrm{t}$-test) and baseline CMT $(429.40 \pm 96.19 \mu \mathrm{m}$ and $425.07 \pm 90.30 \mu \mathrm{m}$, respectively, $\mathrm{t}=0.198, \mathrm{p}=0.8$, independent $\mathrm{t}$-test $)$. There was no significant difference between the groups by means of age at presentation $(\mathrm{t}=-0.140, \mathrm{p}=0.8$, independent $\mathrm{t}$-test $)$,

\begin{tabular}{|c|c|c|c|}
\hline Features & Group 1 & Group 2 & $P$ value \\
\hline Age (years) & $35.76 \pm 6.21$ & $35.96 \pm 6.22$ & $0.8^{*}$ \\
\hline Male:female & $61: 6$ & $19: 7$ & $0.03 \dagger$ \\
\hline $\begin{array}{l}\text { Duration of } \\
\text { symptoms } \\
\text { (days) }\end{array}$ & $14.46 \pm 5.63$ & $20.58 \pm 4.73$ & $<0.001^{*}$ \\
\hline $\begin{array}{l}\text { Baseline } \\
\text { BCVA } \\
\text { (LogMAR) }\end{array}$ & $0.47 \pm 0.37$ & $0.44 \pm 0.24$ & $0.7^{\star}$ \\
\hline $\begin{array}{l}\text { Baseline CMT } \\
(\mu \mathrm{m})\end{array}$ & $429.40 \pm 96.19$ & $425.07 \pm 90.30$ & $0.8^{*}$ \\
\hline $\begin{array}{l}\text { Smoking } \\
\text { (yes:no) }\end{array}$ & $21: 46$ & $6: 20$ & $0.4 \ddagger$ \\
\hline HTN (yes:no) & $3: 64$ & $4: 22$ & $0.09 \dagger$ \\
\hline DM (yes:no) & $0: 67$ & $2: 24$ & $0.07 \dagger$ \\
\hline $\begin{array}{l}\text { Final BCVA } \\
\text { (LogMAR) }\end{array}$ & $0.15 \pm 0.14$ & $0.39 \pm 0.16$ & $<0.001^{*}$ \\
\hline $\begin{array}{l}\text { Final CMT } \\
(\mu \mathrm{m})\end{array}$ & $226.17 \pm 12.66$ & $207.26 \pm 15.72$ & $<0.001^{*}$ \\
\hline
\end{tabular}

*Independent 't' test.

† Fisher's exact test

$\ddagger \chi^{2}$ test

BCVA, best-corrected visual acuity; CMT, central macular thickness.

smoking habit ( $\mathrm{p}=0.4, \chi^{2}$ test), and presence of hypertension or diabetes ( $\mathrm{p}=0.09$, and $\mathrm{p}=0.07$, respectively, Fisher's exact test). Among the 26 patients of group 2, only one had persistence of SRF at 6 months. The patient's SRF had resolved during the examination at the end of 7 months.

The overall average BCVA (LogMAR) improved significantly from $0.46 \pm 0.34$ at baseline to $0.21 \pm 0.18$ ( $\mathrm{t}=7.023$, $\mathrm{p}<0.001$, paired t-test) at the final visit. The final BCVA (LogMAR) was statistically worse in group 2 compared with group $1,0.39 \pm 0.16$ vs $0.15 \pm 0.14(\mathrm{t}=7.156, \mathrm{p}<0.001$, independent t-test).

Likewise the overall average CMT decreased from $428.19 \pm 94.11 \mu \mathrm{m}$ at baseline to $220.89 \pm 15.97 \mu \mathrm{m}$ $(\mathrm{t}=20.689, \mathrm{p}<0.001$, paired $\mathrm{t}$-test $)$ at final visit. The final CMT of the patients of group $1(226.17 \pm 12.66 \mu \mathrm{m})$ was statistically thinner than the normal population $(241.13 \pm 12.95 \mu \mathrm{m}), \quad(\mathrm{t}=-5.338, \mathrm{p}<0.001$, independent t-test); while that of the patients of group $2(207.26 \pm 15.72$ $\mu \mathrm{m})$ was statistically thinner than group $1(\mathrm{t}=-6.029$, $\mathrm{p}<0.001$, independent t-test).

Table 2 shows the brief summary of the baseline OCT findings of the patients. Among the OCT parameters at presentation, the two groups were significantly different only in terms of presence of HRDs $\left(p<0.001, \chi^{2}\right.$ test $)$. There was no significant difference between the two groups by means of presence of PED, RPE bumps and fibrin $\left(\mathrm{p}=0.4, \mathrm{p}=0.1\right.$, and $\mathrm{p}=0.2$, respectively, $\chi^{2}$ test). A Mann-Whitney $\mathrm{U}$ test showed that there was a significant 
Table 2 Brief summary of the baseline OCT findings of the two groups

\begin{tabular}{lllcc}
\hline \multirow{2}{*}{ OCT features } & & \multicolumn{2}{l}{ Distribution among groups (\%) } & \\
\cline { 3 - 4 } & Total no of eyes (\%) & Group 1 & Group2 & P value ( $\chi^{2}$ test) \\
\hline PED & $24(25.80)$ & $16(17.20)$ & $8(8.60)$ & 0.4 \\
HRDs & $33(35.48)$ & $16(17.20)$ & $17(18.27)$ & $<0.001$ \\
RPE bumps & $28(30.10)$ & $17(18.27)$ & $11(11.82)$ & 0.1 \\
Fibrin & $21(22.58)$ & $13(13.97)$ & $8(8.6)$ & 0.2 \\
\hline
\end{tabular}

Percentage represents the ratio among all the eyes in the study with some eyes having more than one feature.

HRD, hyper-reflective dot; OCT, optical coherence tomography; PED, pigment epithelial detachment; RPE, Retinal Pigment Epithelium.

difference $(\mathrm{U}=481.50, \mathrm{p}<0.001)$ between the two groups by means of numbers of HRDs. The median number of HRDs was 0 (Min 0, Max 5) for group 1 compared with 1.5 (Min 0, Max 6) for group 2.

Table 3 shows that female sex and presence of HRDs and RPE bumps in the baseline OCT were associated with significantly longer duration of SRF resolution $(\mathrm{t}=2.212, \mathrm{p}=0.04, \mathrm{t}=3.554, \mathrm{p}=0.001$, and $\mathrm{t}=2.602, \mathrm{p}=0.01$, respectively, independent t-test). However among these factors, presence of HRDs was the only factor associated with significantly poorer final visual outcome $(\mathrm{t}=3.835$, $\mathrm{p}=<0.001$, independent t-test). We also found that the presence of HRDs and RPE bumps in the baseline OCT was associated with significantly thinner final CMT $(\mathrm{t}=-2.913$, $\mathrm{p}=0.004$ and $\mathrm{t}=-2.581, \mathrm{p}=0.01$, respectively, independent t-test). We observed that the actual number of HRDs in the baseline OCT had a significant correlation with the SRF resolution time $(\mathrm{r}=+0.336, \mathrm{p}=0.001)$; the final CMT $(\mathrm{r}=-0.242, \mathrm{p}=0.01)$; and the final BCVA in LogMAR $(\mathrm{r}=+0.309, \mathrm{p}=0.001)$. We found that there was a significant difference between patients with HRDs and those without HRDs in their baseline OCT when considered jointly on the variables: duration of SRF resolution, final CMT and final BCVA, Wilk's $\Lambda=0.815, \mathrm{~F} \quad(3,89)=6.729, \mathrm{p}=<0.001$, partial $\eta 2=0.185$. A separate ANOVA was conducted for each dependent variable, with each ANOVA evaluated at an alpha level of 0.01667 . There was a significant difference between the patients with regard to presence or absence of HRDs in their baseline OCT on: (1) duration of SRF resolution, $\mathrm{F}(1,91)=16.309$, $\mathrm{p}<0.001$, partial $\eta 2=0.152$; (2) final CMT, $\mathrm{F}(1,91)=8.488, \mathrm{p}=0.004$, partial $\eta 2=0.085$ and (3) final BCVA, $F(1,91)=14.704, p<0.001$, partial $\eta 2=0.139$, with patients with HRDs having longer duration of SRF resolution, thinner final CMT and poorer final BCVA that those without HRDs. Age at presentation did not have any significant correlation with the duration of SRF resolution $(\mathrm{r}=-0.012, \mathrm{p}=0.45)$; final CMT $(\mathrm{r}=+0.003, \mathrm{p}=0.48)$ and final BCVA in LogMAR $(r=-0.018, p=0.43)$.

\begin{tabular}{|c|c|c|c|c|c|c|}
\hline Factors & $\begin{array}{l}\text { Duration of } \\
\text { SRF resolution } \\
\text { (months) }\end{array}$ & $P$ value ${ }^{*}$ & Final LogMAR BCVA & P value* & Final CMT $(\boldsymbol{\mu} \mathrm{m})$ & P value* \\
\hline \multicolumn{7}{|l|}{ Gender } \\
\hline Male (80) & $2.46 \pm 1.45$ & 0.04 & $0.20 \pm 0.18$ & 0.14 & $221.96 \pm 15.92$ & 0.10 \\
\hline Female (13) & $3.76 \pm 2.04$ & & $0.28 \pm 0.18$ & & $214.30 \pm 15.22$ & \\
\hline \multicolumn{7}{|l|}{ HRDs } \\
\hline Yes (33) & $3.48 \pm 1.90$ & 0.001 & $0.31 \pm 0.19$ & $<0.001$ & $214.63 \pm 17.36$ & 0.004 \\
\hline No (60) & $2.18 \pm 1.20$ & & $0.16 \pm 0.15$ & & $224.33 \pm 14.15$ & \\
\hline \multicolumn{7}{|l|}{ RPE bumps } \\
\hline Yes (28) & $3.28 \pm 1.78$ & 0.01 & $0.24 \pm 0.20$ & 0.31 & $214.57 \pm 17.90$ & 0.01 \\
\hline No (65) & $2.36 \pm 1.45$ & & $0.20 \pm 0.17$ & & $223.61 \pm 14.36$ & \\
\hline \multicolumn{7}{|l|}{ PED } \\
\hline Yes (24) & $2.95 \pm 1.68$ & 0.27 & $0.21 \pm 0.20$ & 0.97 & $221.95 \pm 15.81$ & 0.70 \\
\hline No (69) & $2.53 \pm 1.57$ & & $0.22 \pm 0.17$ & & $220.52 \pm 16.12$ & \\
\hline \multicolumn{7}{|l|}{ Fibrin } \\
\hline Yes (21) & $3.00 \pm 1.84$ & 0.25 & $0.24 \pm 0.17$ & 0.45 & $217.23 \pm 17.54$ & 0.23 \\
\hline No (72) & $2.54 \pm 1.52$ & & $0.21 \pm 0.19$ & & $221.95 \pm 15.44$ & \\
\hline
\end{tabular}

*Independent t-test.

BCVA, best-corrected visual acuity; CMT, central macular thickness; HRDs, hyper-reflective dots; OCT, optical coherence tomography; RPE, Retinal pigment epithelium; SRF, subretinal fluid. 
We observed that the duration of symptoms showed significant correlation with the duration of SRF resolution $(\mathrm{r}=+0.338, \mathrm{p}<0.001)$ and final BCVA in LogMAR $(\mathrm{r}=+0.210, \mathrm{p}=0.02)$ but failed to show any significant correlation with the final CMT $(\mathrm{r}=-0.111, \mathrm{p}=0.14)$. The baseline BCVA in LogMAR showed significant correlation with the final BCVA in LogMAR $(r=+0.287, p=0.003)$ and the final CMT $(r=-0.19, \mathrm{p}=0.03)$ but failed to show any significant correlation with the SRF resolution time $(\mathrm{r}=+0.012, \mathrm{p}=0.4)$. However, the baseline CMT had no significant correlation with duration of SRF resolution $(\mathrm{r}=-0.007, \mathrm{p}=0.47)$ or final CMT $(\mathrm{r}=-0.07, \mathrm{p}=0.23)$ or final BCVA ( $\mathrm{r}=+0.043, \mathrm{p}=0.34)$. We observed that the SRF resolution time had a strong negative correlation with the final CMT $(\mathrm{r}=-0.589, \mathrm{p}<0.001)$ and a strong positive correlation with final BCVA in LogMAR ( $\mathrm{r}=+0.599$, $\mathrm{p}<0.001)$. Likewise the final BCVA in LogMAR had a very strong negative correlation with the final CMT $(r=-0.783$, $\mathrm{p}<0.001)$. We ran a multiple regression analysis to predict the final BCVA in LogMAR from both duration of SRF resolution and final CMT. These variables were statistically significant in prediction of final BCVA, $\mathrm{F}(2,90)=80.927$, $\mathrm{p}<0.001, \mathrm{R}^{2}=0.643$. The standardised coefficients beta for duration of SRF resolution and final CMT was 0.212 and -0.659 , respectively. Both the variables added statistical significance to the prediction, $\mathrm{p}<0.05$.

For visualisation of these correlations, we overlaid linear regression models of four pairs of data on the scatter plots: duration of symptoms vs duration of SRF resolution; duration of SRF resolution vs final CMT; duration of SRF resolution vs final BCVA in LogMAR; and final CMT vs final BCVA in LogMAR (figure 2).

\section{DISCUSSION}

This study supports the hypothesis that prolonged absence of contact between the photoreceptor cells and the RPE cells results in poorer visual outcome in cases of CSCR. The poor vision has been attributed to the damage to the outer retina. ${ }^{13}{ }^{18-20}$ However, the actual duration required for this irreversible damage to occur is a crude estimation. This is because in majority of the patients, the fellow eye is usually healthy, and thus the duration of symptoms reported by the patient is an unreliable measure. So this designation of chronicity in CSCR is somewhat inconsistent. Some authors define chronicity as persistence of fluid for at least 6 months, ${ }^{21}$ while others as 3 months. ${ }^{22-24}$ We divided the patients in our study into two groups by defining chronicity as persistence of SRF fluid for more than 3 months.

Acute CSCR is believed to be a self-limiting disease. The neurosensory retina usually reattaches within 3-4 months in majority of the cases. ${ }^{21}$ Thus observation is the first-line of treatment in most of the cases. ${ }^{25}$ Though longer duration of SRF resolution has been associated with worse structural and functional retinal outcome, there has been no consensus regarding the most suitable treatment and the optimal timing for intervention in CSCR patients. We thus studied the patient's baseline
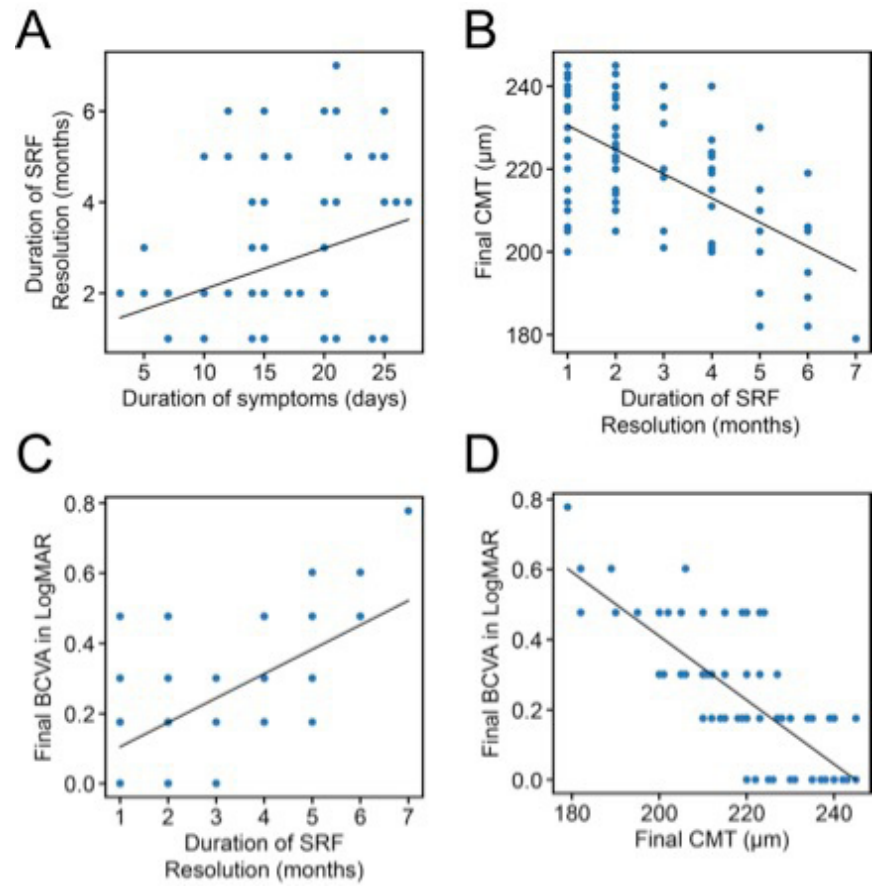

Figure 2 Scatter plots with linear regression (black line) showing relation between: duration of symptoms(days) versus duration of SRF resolution (months) (A); duration of SRF resolution (months) versus final CMT $(\mu \mathrm{m})(B)$; duration of SRF resolution (months) versus final BCVA in LogMAR (C) and Final CMT $(\mu \mathrm{m})$ versus final BCVA in LogMAR (D). BCVA, best-corrected visual acuity; CMT, central macular thickness; SRF, subretinal fluid.

factors that helped us to predict the clinical course of the disease.

We observed that all the patients with CSCR developed macular thinning after resolution of the SRF. Longer time for SRF resolution was associated with thinner final CMT and worse final BCVA. We also found that eyes with thinner final CMT were associated with worse BCVA at both baseline and at the final visit. Similar correlation between duration of SRF resolution with both final CMT and final visual outcome were noted by Aggio $e t a l^{20}$ and Wang $e t a l .^{26}$ Other studies too have reported atrophy of the fovea after resolution of the SRF in cases of CSCR and have correlated the foveal thickness with the final visual acuity. ${ }^{27} 28$

HRD is one of the various OCT tomographic factors often reported in cases of CSCR. ${ }^{16} 1829$ These HRDs are believed to be macrophages and disintegrated outer photoreceptor remnants that become deposited in the subretinal or the intraretinal space secondary to failed pumping action of the RPE. ${ }^{163031}$ The overall incidence of HRDs in our study was $35.48 \%$. This is relatively low compared with the incidence rate of $66 \%, 65 \%, 57.4 \%$ and $50 \%$ in the studies by Yalcinbayir et al, ${ }^{16}$ Maruko et $a l^{29}$ Lai $e t a l^{18}$ and Suwal $e t a l^{32}$, respectively. Lee $e t a l^{17}$ stated that increased number of HRDs was associated with recurrences. In their retrospective study, Song et $a l^{15}$ found that HRDs were rarely seen in cases with acute 
CSCR and more commonly observed in eyes with early chronic and late chronic CSCR. So the reason behind this low incidence of HRDs in our study might be the exclusion of the cases with recurrences and those having symptoms for more than 30 days before presentation to the hospital.

The presence of intraretinal and/or subretinal HRDs in CSCR has been associated with poor visual prognosis and the need for early intervention. ${ }^{16}{ }^{18}$ In our study presence of HRDs was associated with significantly longer time for SRF resolution, thinner final CMT and poorer visual outcome. We also observed that the increased number of HRDs in baseline OCT too was associated with significantly longer time for SRF resolution, thinner final CMT and worse final visual outcome. In their retrospective study, Lee $e t a l^{17}$ too observed that the number of HRDs observed in baseline SD-OCT correlated positively with both the duration of SRF resolution and the duration of visual recovery. However, they did not observe any correlation between number of HRDs and the final visual outcome. In their study, Suwal $e t a l^{32}$ found that eyes with HRDs had persistence of SRF at the end of 3 months and were associated with poor visual outcome.

The overall incidence of RPE bumps in our study was $30.10 \%$. The incidence of RPE bumps has been reported to be $46.4 \%, 8.1 \%, 45.2 \%$, and $62.5 \%$ in studies by Yalcinbayir et al, ${ }^{16}$ Lee et al, ${ }^{17}$ Daruich et $a l,{ }^{33}$ and Suwal $e t a l .{ }^{32}$ We observed that the presence of RPE bumps in the baseline OCT was associated with significantly longer time for SRF resolution, and thinner final CMT, but it did not have any significant effect on the final visual outcome. No such relations were observed in other studies. ${ }^{17} 18$

We observed that eyes with longer duration of symptoms took significantly longer time for SRF resolution and were associated with thinner final CMT and worse final visual outcome. Malik et $a l^{34}$ found that shorter duration of symptoms was associated with better visual outcome, but Furuta $e t a l^{28}$ did not find any correlation between duration of symptoms with both BCVA and foveal thickness after the resolution of the SRF.

We observed that worse baseline BCVA was associated with thinner final CMT and poorer final BCVA, but bore no significant correlation to duration of SRF resolution. Malik et $a l^{34}$ also commented that baseline BCVA was a reliable predictor of final visual outcome in CSCR and Lee $e t a l^{17}$ stated that worse baseline BCVA was associated with increased time for SRF resolution.

The findings regarding association between age at presentation and gender with disease duration and final visual outcome is different in different studies. We did not find any correlation between disease duration, final CMT, and final visual outcome with age at presentation. In our study female gender was associated with longer disease duration but had no association with final CMT and final visual outcome. Aggio et $a t^{20}$ too did not find any significant association between age, gender and final visual acuity. However, there are studies that have reported that women of age $\geq 50$ take longer time for disease resolution ${ }^{35}$ and is an indication for early intervention. ${ }^{18}$ Daruich $e t a l^{33}$ found that age $\geq 40$ years was an independent factor associated with longer disease duration, but Lee $e a^{17}$ found no relation between duration of SRF resolution and duration of visual acuity recovery with the age of the patient.

In this study, all the patients received topical NSAID for 1 month on diagnosis of the disease as per the hospital's treatment protocol. Few cases have been reported to have developed CSCR following the topical use of latanoprost eye drops, suggesting that prostaglandins too might have a role in the pathogenesis of CSCR ${ }^{36}{ }^{37}$ Studies have shown early resorption of the SRF in cases of CSCR with the use of topical NSAIDs. ${ }^{38-40}$ Likewise the use of oral NSAID like aspirin too has been associated with faster visual improvement and reduced rates of CSCR recurrences. ${ }^{41} 42$

Though the overall average final BCVA of our study population improved significantly $(\mathrm{p}<0.001)$, the final visual acuity of the patients in whom the duration of SRF resolution was more than 3 months did not change significantly from the baseline value $(t=1.009, p=0.32$, paired t-test). All the patients in our study had received topical NSAID for the first month, but still, 26 (27.95\%) eyes out of 93 eyes developed chronic CSCR (duration of SRF resolution $>3$ months) and poor final visual acuity. Based on our assumption that the effects of NSAID was similar on all the eyes, we believe that those cases of treatment naïve acute idiopathic CSCR occurring in females and/or those associated with HRDs and/or RPE bumps in baseline OCT are more likely to develop chronic disease.

The retrospective nature and the lack of control group in the study precluded us from understanding the natural course of the disease. Since the duration of symptoms is significantly less in group 1 patients compared with group 2 , it might exaggerate the difference in duration of the entire CSR episode from onset of symptoms to resolution of SRF between the two groups.

In conclusion, in cases of treatment naïve acute idiopathic CSCR, patient's baseline clinicodemographic and OCT features can be used to predict the course of the disease and the visual outcome

Acknowledgements The authors would like to thank Santosh Koirala, PhD, for his assistance in statistics.

Contributors AP and PJ planned the study. AP was involved in data collection and analysis and drafting of the first manuscript. PJ reviewed the literature and edited the manuscript. Both the authors approved the final manuscript.

Funding The authors have not declared a specific grant for this research from any funding agency in the public, commercial or not-for-profit sectors.

Competing interests None declared.

Patient consent for publication Not required.

Ethics approval Local ethical committee board of the Mechi Eye Hospital.

Provenance and peer review Not commissioned; externally peer reviewed.

Data availability statement All data relevant to the study are included in the article. 
Open access This is an open access article distributed in accordance with the Creative Commons Attribution Non Commercial (CC BY-NC 4.0) license, which permits others to distribute, remix, adapt, build upon this work non-commercially, and license their derivative works on different terms, provided the original work is properly cited, appropriate credit is given, any changes made indicated, and the use is non-commercial. See: http://creativecommons.org/licenses/by-nc/4.0/.

ORCID iDs

Anil Parajuli http://orcid.org/0000-0003-0124-152X

Purushottam Joshi http://orcid.org/0000-0001-9428-0266

\section{REFERENCES}

1 Donald J, Gass M. Pathogenesis of disciform detachment of the neuroepithelium: II. idiopathic central serous choroidopathy. Am J Ophthalmol 1967;63:1.

2 Kitzmann AS, Pulido JS, Diehl NN, et al. The incidence of central serous chorioretinopathy in Olmsted County, Minnesota, 1980-2002. Ophthalmology 2008;115:169-73.

3 Tsai D-C, Chen S-J, Huang C-C, et al. Epidemiology of idiopathic central serous chorioretinopathy in Taiwan, 2001-2006: a populationbased study. PLoS One 2013;8:e66858.

4 Spaide RF, Campeas L, Haas A, et al. Central serous chorioretinopathy in younger and older adults. Ophthalmology 1996;103:2070-80.

5 Tittl MK, Spaide RF, Wong D, et al. Systemic findings associated with central serous chorioretinopathy. Am J Ophthalmol 1999;128:63-8.

6 Spitznas M, Huke J. Number, shape, and topography of leakage points in acute type I central serous retinopathy. Graefes Arch Clin Exp Ophthalmol 1987;225:437-40.

7 Hayashi K, Hasegawa Y, Tokoro T. Indocyanine green angiography of central serous chorioretinopathy. Int Ophthalmol 1986;9:37-41.

8 Scheider A, Nasemann JE, Lund OE. Fluorescein and indocyanine green angiographies of central serous choroidopathy by scanning laser ophthalmoscopy. Am J Ophthalmol 1993;115:50-6.

9 Piccolino FC, Borgia L. Central serous chorioretinopathy and indocyanine green angiography. Retina 1994;14:231-42.

10 Guyer DR, Yannuzzi LA, Slakter JS, et al. Digital indocyanine green videoangiography of central serous chorioretinopathy. Arch Ophthalmol 1994;112:1057-62.

11 Baran NV, Gürlü VP, Esgin H. Long-Term macular function in eyes with central serous chorioretinopathy. Clin Exp Ophthalmol 2005;33:369-72.

12 Folk JC, Thompson HS, Han DP, et al. Visual function abnormalities in central serous retinopathy. Arch Ophthalmol 1984;102:1299-302.

13 Nicholson B, Noble J, Forooghian F, et al. Central serous chorioretinopathy: update on pathophysiology and treatment. Surv Ophthalmol 2013;58:103-26.

14 Mrejen S, Sarraf D, Mukkamala SK, et al. Multimodal imaging of pigment epithelial detachment: a guide to evaluation. Retina 2013;33:1735-62

15 Song IS, Shin YU, Lee BR. Time-Periodic characteristics in the morphology of idiopathic central serous chorioretinopathy evaluated by volume scan using spectral-domain optical coherence tomography. Am J Ophthalmol 2012;154:366-75.

16 Yalcinbayir O, Gelisken O, Akova-Budak B, et al. Correlation of spectral domain optical coherence tomography findings and visual acuity in central serous chorioretinopathy. Retina 2014;34:705-12.

17 Lee $\mathrm{H}$, Lee J, Chung $\mathrm{H}$, et al. Baseline spectral domain optical coherence tomographic hyperreflective foci as a predictor of visual outcome and recurrence for central serous chorioretinopathy. Retina 2016;36:1372-80.

18 Lai W-Y, Tseng C-L, Wu T-T, et al. Correlation between baseline retinal microstructures in spectral-domain optic coherence tomography and need for early intervention in central serous chorioretinopathy. BMJ Open Ophthalmol 2017;2:e000054.

19 Loo RH, Scott IU, Flynn HW, et al. Factors associated with reduced visual acuity during long-term follow-up of patients with idiopathic central serous chorioretinopathy. Retina 2002;22:19-24.
20 Aggio FB, Roisman L, Melo GB, et al. Clinical factors related to visual outcome in central serous chorioretinopathy. Retina 2010;30:1128-34.

21 Yannuzzi LA. Central serous chorioretinopathy: a personal perspective. Am J Ophthalmol 2010;149:361-3.

22 Chan W-M, Lai TYY, Lai RYK, et al. Safety enhanced photodynamic therapy for chronic central serous chorioretinopathy: one-year results of a prospective study. Retina 2008;28:85-93.

23 Reibaldi M, Cardascia N, Longo A, et al. Standard-fluence versus low-fluence photodynamic therapy in chronic central serous chorioretinopathy: a nonrandomized clinical trial. Am J Ophthalmol 2010;149:307-15.

24 Shin JY, Woo SJ, Yu HG, et al. Comparison of efficacy and safety between half-fluence and full-fluence photodynamic therapy for chronic central serous chorioretinopathy. Retina 2011;31:119-26.

25 Yannuzzi LA. Type-A behavior and central serous chorioretinopathy. Retina 1987;7:111-31.

26 Wang MSM, Sander B, Larsen M. Retinal atrophy in idiopathic central serous chorioretinopathy. Am J Ophthalmol 2002;133:787-93.

27 Eandi CM, Chung JE, Cardillo-Piccolino F, et al. Optical coherence tomography in unilateral resolved central serous chorioretinopathy. Retina 2005;25:417-21.

28 Furuta M, lida T, Kishi S. Foveal thickness can predict visual outcome in patients with persistent central serous chorioretinopathy. Ophthalmologica 2009;223:28-31.

29 Maruko I, lida T, Ojima A, et al. Subretinal dot-like precipitates and yellow material in central serous chorioretinopathy. Retina 2011:31:759-65.

30 Matsumoto H, Kishi S, Otani T, et al. Elongation of photoreceptor outer segment in central serous chorioretinopathy. Am J Ophthalmol 2008;145:162-8.

31 Kon Y, lida T, Maruko I, et al. The optical coherence tomographyophthalmoscope for examination of central serous chorioretinopathy with precipitates. Retina 2008;28:864-9.

32 Suwal B, Khadka D, Shrestha A, et al. Baseline predictive factors of visual outcome and persistence of subretinal fluid based on morphologic changes in spectral domain optical coherence tomography in patients with idiopathic central serous chorioretinopathy. Clin Ophthalmol 2019;13:2439-44.

33 Daruich A, Matet A, Marchionno L, et al. Acute central serous chorioretinopathy: factors influencing episode duration. Retina 2017;37:1905

34 Malik A, Gupta A, Mithal C, et al. Central serous chorioretinopathy: correlation of structural changes on optical coherence tomography with visual outcomes. Delta Journal of Ophthalmology 2017;18:37-43.

35 Perkins SL, Kim JE, Pollack JS, et al. Clinical characteristics of central serous chorioretinopathy in women. Ophthalmology 2002;109:262-6.

36 Artunay O, Senel A, Sengul A, et al. Central serous chorioretinopathy associated with topical latanoprost therapy. Ocul Immunol Inflamm 2011;19:453-5.

37 Ayhan Tuzcu E, Keskin U, Coskun M, et al. Bilateral serous detachment associated with latanoprost/timolol fixed combination use: a report of one phakic case. Case Rep Ophthalmol Med 2012;2012:1-3.

38 Alkin Z, Osmanbasoglu OA, Ozkaya A, et al. Topical nepafenac in treatment of acute central serous chorioretinopathy. Med Hypothesis Discov Innov Ophthalmol 2013;2:96.

39 Khan NAet al. Topical Bromfenac in the treatment of central serous chorioretinopathy. Adv Ophthalmol Vis Syst 2017;7:00248.

40 Bahadorani S, Maclean K, Wannamaker K, et al. Treatment of centra serous chorioretinopathy with topical NSAIDs. Clin Ophthalmol 2019;13:1543-8

41 Caccavale A, Imparato M, Romanazzi F, et al. A new strategy of treatment with low-dosage acetyl salicylic acid in patients affected by central serous chorioretinopathy. Med Hypotheses 2009:73:435-7.

42 Caccavale A, Romanazzi F, Imparato M, et al. Low-Dose aspirin as treatment for central serous chorioretinopathy. Clin Ophthalmol 2010;4:899-903. 